\title{
Uma contribuição fenomenológica para a História das Matemáticas: o problema da origem dos números
}

\section{A phenomenological contribution to the History of Mathematics: the problem of the origin of numbers}

Dndo. Carlos Eduardo de Carvalho Vargas

carlos.vargas@ibge.gov.br

Pontifícia Universidade Católica do

Paraná | IBGE, Brasil
Prof. Dr. Cleverson Leite Bastos

leite.bastos@pucpr.br

Pontifícia Universidade Católica do

Paraná, Brasil

A partir da perspectiva da filosofia da ciência de Edmund Husserl, o artigo aplica a concepção fenomenológica de história na compreensão da origem dos números. Analisando o texto A questão da história da geometria como um problema histórico-intencional, é possível generalizar a contribuição fenomenológica para a história das matemáticas. O artigo relaciona a questão da historicidade com outros conceitos apresentados em A crise das ciências europeias e a fenomenologia transcendental, como sedimentação e mundo da vida (Lebenswelt), problematizando a relação entre história empírica e história a priori. Para abordar especificamente a questão da origem dos números, o artigo também retoma algumas noções de Filosofia da Aritmética. Na análise final, os autores indicam algumas implicações filosóficas da tarefa de clarificar o sentido do número.

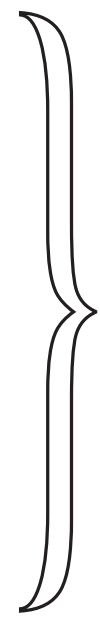

\section{PALAVRAS-CHAVE}

Edmund Husserl; Fenomenologia. Filosofia da Ciência; História das Matemáticas

From the perspective of the Edmund Husserl's philosophy of science, the paper applies the phenomenological conception of history in understanding the origin of numbers. Analyzing the text The question of the origin of geometry considered as a problem of intentional history, it is also possible to generalize a phenomenological contribution to the history of mathematics. The article relates the question of historicity with other concepts presented in The Crisis of European Sciences and Transcendental Phenomenology, such as sedimentation and lifeworld (Lebenswelt), questioning the relationship between empirical history and history a priori. To specifically approach the question of the origin of the numbers, the article also revisits notions of Philosophy of Arithmetic. In the final analysis, the authors indicate some philosophical implications of the task of clarifying the meaning of the number.

\section{KEYWORDS}

Edmund Husserl; Phenomenology; Philosophy of Science; History of Mathematics 


\section{A Crise e a filosofia da ciência de Edmund Husserl}

Edmund Husserl deve uma parte da sua formação científica aos matemáticos Karl Weierstrass, do qual foi assistente entre 1883 e 1884, Leopold Kronecker e Leo Königsberger, que orientou, na Universidade de Viena, seu doutorado em matemática, obtido com a tese Contribuições ao Cálculo das Variações. Quando esteve em Halle, Husserl também foi influenciado por Georg Cantor, o qual desenvolveu a teoria dos conjuntos (HILL, 1997; IERNA, 2012; VARGAS, 2013).

As matemáticas, especialmente a aritmética, também foram objetos de análise dos primeiros trabalhos filosóficos de Edmund Husserl. Ainda em Halle, ele escreveu seu trabalho Sobre o Conceito de Número (1887), além de Filosofia da Aritmética: Investigações Lógicas e Psicológicas (1891). Também se pode destacar a obra Investigações Lógicas (1900-1901), especialmente seu primeiro volume, Prolegômenos à Lógica Pura (1900). Nesses primeiros trabalhos, o autor já pensava a divisão das atividades do filósofo e do matemático. Husserl chamou o cientista de "técnico engenhoso", reservando ao filósofo a tarefa de analisar criticamente a atividade científica em um grau de profundidade que a matemática não poderia obter por si mesma: "Há aqui que atender a que o matemático não é, na verdade, o teorético puro, mas tão-só o técnico engenhoso, por assim dizer, o mestre-de-obras que, com respeito às conexões formais, constrói a teoria como uma obra de arte técnica"1. (Hua, XVIII, pp. 254-255).

Na Universidade de Göttingen, entre 1901-1916, Edmund Husserl também foi influenciado pelo matemático David Hilbert, o qual relacionou os fundamentos formais da lógica e da matemática com suas aplicações às ciências empíricas. Contudo, eles divergiram na interpretação da relação entre ciência, técnica e história. Ao analisar a ciência moderna a partir da perspectiva da história da filosofia, Husserl concebeu a ciência em uma perspectiva histórica no contexto maior da cultura europeia, a qual buscava uma teoria universal amplamente abrangente (HEELAN, 1989, pp. 388-389; VARGAS, 2013).

A obra $A$ crise das ciencias europeias e a fenomenologia transcendental, doravante citada como Crise, reuniu alguns textos em que Husserl (Hua, VI) descreveu a crise da ciência de seu tempo como expressão da crise radical da vida na humanidade europeia. A perspectiva husserliana provoca interesse inclusive pela sua importância no movimento fenomenológico, mas também pela sua filosofia da lógica e da matemática.

1 As indicações das obras de Edmund Husserl serão feitas em relação à coleção Husserliana (Hua), indicando o volume da obra e, quando for o caso, a seção (§). Uma exceção será feita para a obra Experiência e Juízo, a qual foi publicada fora da coleção Husserliana. 
Edmund Husserl contribuiu com a filosofia da ciência por meio de uma crítica à tradição galilaica das ciências empíricas. Ele não aceitou a redução das ciências modernas aos seus aspectos meramente computacionais e formais, prejudicando aspectos significativos da experiência em favor da tecnicização e da matematização. Ao perceber que a teoria "objetiva" estruturada matematicamente estava substituindo o único mundo real, Husserl (Hua, VI) procurou resgatar o sentido original da ciência a partir da noção de mundo da vida (Lebenswelt), entendida como um domínio de evidências originárias a partir do qual as idealizações científicas deveriam ser validadas.

A razão, a filosofia e as ciências também foram problematizadas, por Husserl, no texto $A$ ingenuidade da ciência (Hua, XXIX), que foi escrito provavelmente em 1934. Husserl procurava resgatar autenticamente o ideal de uma filosofia de alcance universal que havia sido buscado na modernidade. $\mathrm{O}$ autor propôs a compreensão da história interna da filosofia, refletindo criticamente sobre a intenção original da tarefa filosófica. O pensamento autêntico deveria clarificar os pressupostos que não foram questionados pelos filósofos anteriores (Hua, XXIX; SILVA, 2009).

No caso das ciências, inclusive das matemáticas, seria preciso superar filosoficamente a ingenuidade de voltar-se apenas às práticas e aos fatos científicos, resgatando fenomenologicamente o sentido da ciência enquanto atividade humana e retomando alguns valores que foram esquecidos: "essa ingenuidade só pode ser desfeita a partir de uma reflexão radical sobre a vida da consciência enquanto fonte constituidora de todos os sentidos" (SILVA, 2009, p. 656).

\section{Da origem da geometria à concepção fenomenológica da história}

Em relação ao tema da temporalidade e da historicidade na fenomenologia, há uma referência fundamental em um estudo realizado pelo próprio Husserl. Trata-se do artigo A origem da geometria considerada como um problema histórico-intencional. Escrito em 1936, em um momento histórico no qual o autor, por ser judeu, não poderia ter suas obras publicadas na Alemanha, o artigo foi publicado postumamente em Bruxelas, em 1939, na Revue internationale de philosophie. Sob a responsabilidade dos Arquivos Husserl da Universidade de Louvain, o texto seria republicado como um dos apêndices do sexto volume da edição crítica das obras de Husserl (coleção Husserliana). Depois, o artigo seria divulgado simplesmente com o nome como foi traduzido por Jacques 
Derrida, em 1962, para o francês, e por David Carr, em 1970, para o inglês: $A$ origem da geometria, como citaremos doravante.

Em $A$ origem da geometria, o autor analisou como a geometria se desenvolveu historicamente, passando das atividades práticas relacionadas à medição da terra até tornar-se ciência de objetos ideais puros visando uma idealização conceitual. Husserl tentou descobrir como a geometria, enquanto disciplina matemática, continuou existindo em uma "tradição" histórica. Ele analisa a geometria como um caso exemplar para as formas de idealização, nas quais os significados são preservados no decorrer da história: "a ciência [...], em particular, a geometria, não pode deixar de ter um começo histórico” (Hua, VI, p. 367).

Para Husserl, o desenvolvimento das culturas e das ciências não podem ser entendidos filosoficamente sem uma análise profunda da historicidade (Geschichtlichkeit) que investigue o mundo da vida e as estruturas a priori fundamentais para as diversas atividades humanas (COHEN; MORAN, 2012, pp. 232-233; VARGAS, 2013):

Todo questionamento e explanação históricos em sentido usual pressupõem já a história como horizonte universal de questionamento, não explicitamente, mas como horizonte de certeza implícita que, em toda a indeterminação própria do plano de fundo vago, é o pressuposto de querer buscar e estabelecer determinados fatos (Hua, VI, p. 382).

Para explicar o desenvolvimento da geometria, Husserl apresentou uma reflexão profunda sobre o sentido da historicidade. Ele também analisou a relação entre a história empírica e a história a priori. Nos textos publicados em Crise, a busca das "origens" assumiu uma importância destacada, sendo que o autor utiliza o termo origem em dois sentidos: Ursprung, no contexto da justificação e evidência da experiência original, e Urstiftung, relacionado à experiência de eventos que ocorreram em momentos historicamente localizados.

Edmund Husserl problematizou, em $A$ origem da geometria, o aspecto histórico da matemática, a qual está em constante desenvolvimento. Ele considerou os aspectos matemáticos, mas almejava um alcance filosófico que ultrapassasse a metodologia científica propriamente dita. Ele buscou filosoficamente uma fundamentação racional das matemáticas a partir da compreensão da cognição 
na consciência. Nos atos de percepção e compreensão da consciência é possível analisar a constituição do conhecimento matemático (KLUTH, 2010): “compreender-se-á a partir desta situação a razão mais funda da exigência que se espalhou na Modernidade, e que finalmente se impôs universalmente, de uma 'fundamentação teórico-cognoscitiva' das ciências” (Hua, VI, p. 377).

David Carr (2010) argumentou que a preocupação com a história é a principal diferença entre os textos publicados em Crise e os trabalhos anteriores de Husserl. Esta contribuição husserliana agregou uma característica que passou a identificar a fenomenologia como um "projeto de universalidade que está consciente de sua própria particularidade e historicidade"2 (CARR, 2010, p. 99).

As reflexões publicadas em Crise acrescentaram a dimensão histórica à reflexão sobre a constituição do sentido na consciência. Em A origem da geometria, Husserl postula uma unidade entre as diversas tradições que se sucederam na história da geometria. Seu objetivo, por meio da metodologia fenomenológica, era revelar a estrutura essencial da unidade das culturas passadas sedimentadas no momento vivido do presente, onde a evidência pode ser reativada e o sentido continua sendo constituído (SILVA, 2009, p. 656): "este conhecimento, para não permanecer discurso vazio ou generalidade indiferenciada, exige, porém, um estabelecimento metódico, a partir de uma pesquisa realizada a partir do presente, e acerca do presente" (Hua, VI, p. 380).

Para explicar a história da ciência, Edmund Husserl apresentou uma analogia com o fenômeno geológico da sedimentação. Apesar de Husserl pensar especificamente na geometria, o que ele escreveu se relaciona com o conhecimento científico em geral e também com a filosofia. Nas reflexões de Crise, o autor assinalou que as ciências e a filosofia desenvolvem-se em um contexto histórico, onde cada pesquisador individual engaja-se em uma tradição existente. Mais do que uma coleção de questões eternas, temos pesquisas em andamento que herdam questões do passado para levantar novas respostas e, principalmente, novos problemas (CARR, 2010, pp. 96-97).

Conforme Eva-Maria Engelen (2010), a noção de sedimentação também desempenha um papel na tensão específica da historicidade. Um sistema conceitual sedimentado, com "suas configurações, conceitos, proposições ou teorias" (Hua, VI, p. 52), é uma referência para o pesquisador individual, em seu contexto histórico. Na obra Crise, Husserl apresentou uma reflexão sobre a história das ciências na Europa, analisando a sedimentação dos conceitos e buscando

2 No original: "a project of universality that is aware of its own particularity and historicity" (tradução dos autores). 
suas "pressuposições": "a história não é, de antemão, outra coisa senão o movimento vivo da comunidade e da coinclusão da formação e da sedimentação originárias de sentido" (Hua, VI, p. 380).

A análise fenomenológica do "transporte" da evidência original ajuda a entender o vínculo que ainda existe com os conceitos históricos, esclarecendo porque eles ainda apresentam um sentido na atualidade. A importância dessa tarefa filosófica manifesta-se na possibilidade de criticar a maneira como as ciências contemporâneas estão sendo desenvolvidas a partir da evidência original sedimentada (ENGELEN, 2010, pp. 141-142).

Mesmo no trabalho do matemático, há pressupostos em suas construções teóricas (Hua, VI, $\S 9$ h). O conhecimento científico, de modo geral, envolve tipicamente conceitos que se remetem a essências, mas também está relacionado com percepções cotidianas de objetos experimentados em um contexto imediato. Apesar do conhecimento científico, especialmente nas matemáticas, pressupor um contexto pré-científico, nem sempre a descrição dos conceitos científicos parece corresponder à experiência cotidiana. A análise da relação entre as essências e as experiências envolvidas nas ciências implica em esclarecimentos que pressupõem a historicidade (SMITH, 2010). A descoberta e o desenvolvimento dos conceitos científicos estão relacionados com a tradição investigativa de uma comunidade científica: "a nossa existência humana move-se em inúmeras tradições. O mundo da cultura existe, em todas as suas figuras, a partir de tradições" (Hua, VI, p. 366).

O conceito de mundo da vida colabora na compreensão da sedimentação científica, na medida em que é um instrumento para detectar a evidência original, o que foi evidenciado na análise husserliana da história da geometria. $\mathrm{O}$ conhecimento geométrico obtido em práticas de medição, antes da idealização formal da geometria, foi um fundamento de sentido para a teorização geométrica. A evidência geométrica a priori não produz uma verdade autossuficiente ou absoluta (Hua, VI, §9h). A reflexão husserliana sobre a história da geometria mostra que as matemáticas não envolvem apenas um conhecimento a priori. A partir das descobertas histórias sobre a geometria egípcia, cujos aspectos científicos estão sendo reconhecidos, Engelen (2010, pp. 143-144) argumenta que não há uma ciência fora do mundo da vida. A reflexão husserliana sobre a evidência original das ciências desdobra-se, portanto, em pelo menos dois aspectos: por um lado, a sedimentação dos sistemas conceituais científicos e filosóficos; por outro lado, a "virada" para o mundo da vida. 
Relacionando Crise com a obra Experiência e Juízo, Dagfinn Føllesdal (2010, pp. 33-34) destacou três relações husserlianas entre as ciências e o mundo da vida. Em primeiro lugar, para Husserl, o mundo das ciências, como todos os mundos, faz parte do mundo da vida, na medida em que a teoria científica começa, em algum momento, a partir de pressupostos do mundo da vida (Hua, VI; HUSSERL, 1939, § 10). Em segundo lugar, as afirmações científicas adquirem sentido na medida em que estão enraizadas no mundo da vida. Edmund Husserl (Hua, XIII) defendeu que todas opiniões, científicas ou não, fundamentadas ou não, relacionam-se ao mundo da vida, o qual era anterior aos demais. Por último, e não menos importante, as ciências precisam do mundo da vida para serem justificadas, pois elas pretendem descrever aspectos do mundo da vida, de onde procede o horizonte do desenvolvimento possível das mesmas (Hua, VI, § 34).

A abordagem histórica das matemáticas, no contexto fenomenológico, conecta-se com a proposta husserliana de fundamentação do conhecimento a partir da concepção do mundo da vida, mostrando o caminho para a crítica das ciências pela relação entre o "mundo objetivo-científico" e o mundo da vida, conceito que "serve a Husserl para uma crítica radical das ciências, cuja idealização já é resultado de métodos de conhecimento fundados em nossa experiência imediata" (ZILLES, 2007, p. 220)."

Como pode ser exemplificado em sua descrição da origem da geometria, Edmund Husserl está pressupondo uma estrutura de significação a priori relacionada à unidade histórica que atravessa diferentes fases da "tradição" científica na medida em que o passado cultural vai sedimentando-se no presente. Trata-se de uma forma de criticar o relativismo que nega o caráter ideal da matemática, mas também é, principalmente, uma crítica ao absolutismo de quem quer separar as ciências do mundo da vida (TIESZEN, 2005).

\section{A história dos números em uma perspectiva fenomenológica}

$\mathrm{Na}$ análise da história fenomenológica das matemáticas, seguindo o exemplo de Husserl (Hua, VI), surge a questão específica do sentido da historicidade, incluindo a reflexão sobre o seu sujeito e a sua estrutura a priori, incluindo a percepção do tempo: passado, presente, e futuro (VARGAS, 2013). Na perspectiva husserliana, as implicações epistemológicas do conceito de historicidade ultrapassam os limites da pesquisa histórica propriamente dita, abordando problemas que poderiam ser considerados estranhos a uma perspectiva técnica 
ou científica. Seguindo o modelo desenvolvido em A Origem da Geometria, uma história fenomenológica dos números não é uma história no sentido historiográfico habitual. Trata-se de um estudo histórico influenciado pela fenomenologia e, portanto, foca os atos constitutivos da consciência abordando seus conteúdos por meio daquilo que é dado diretamente à intuição. $\mathrm{O}$ autor pretendia, reativando a matéria originária que motivou a elaboração dos conceitos, alcançar um conhecimento autêntico dos objetos científicos, inclusive da natureza e do mundo (SILVA, 2009, p. 656).

Edmund Husserl (Hua, XXIX, pp. 27-36) criticou a "ingenuidade" da ciência que não considera a historicidade inerente à prática científica. Além de saber que há uma história das ciências e de perceber-se inserido em uma tradição, Husserl exige a diferenciação entre a evidência empírica, da prática científica e da representação sensível, e a evidência fenomenológica, a qual procede da origem das idealidades após o tratamento rigoroso dos conteúdos científicos, especialmente das proposições e dos conceitos envolvidos nas teorias, mas também faz relações com alguns conteúdos pré-científicos (SILVA, 2009, pp. 656-657).

Para Husserl, a história apresenta uma estrutura intrínseca que ultrapassa os limites da história fática. Além dos fatos propriamente ditos, é preciso, mesmo nas ciências matemáticas, levantar a temática do solo onde foram sedimentados os sentidos, resgatando premissas que se remetem às suas origens no mundo pré-científico. $\mathrm{O}$ autor percebeu que a consciência humana não está passiva diante de um domínio qualquer de objetos, mas desempenha um processo cognitivo relacionado com fatores históricos (CARR, 2010, p. 96).

O objetivo do fenomenólogo não é formular as questões sobre os números em termos de teorias matemáticas, nem utilizar os números com algum objetivo prático. A metodologia fenomenológica possibilita investigar a estrutura $a$ priori que subjaz como solo para as possibilidades desenvolvidas na história das matemáticas. Como Husserl já havia explicado nos Prolegômenos à Lógica Pura, o fundamento filosófico do conhecimento científico não pode ser desprezado: "só a pesquisa filosófica completa as realizações científicas do pesquisador da natureza e do matemático, de modo a completar o conhecimento teorético puro e genuíno" (Hua XVIII, p. 255-256).

$\mathrm{Na}$ perspectiva fenomenológica, portanto, o estudo da origem do número não é simplesmente uma análise lógica da significação do número (DE BOER, 1978, p. 69), mas implica na clarificação do sentido de número, que é a descrição do fenômeno pelo qual o conceito foi abstraído. Husserl perguntou-se como um determinado conhecimento científico passa da "origem intrapessoal", 
na mente de seu descobridor, à objetividade ideal, obtendo uma configuração de validade universal (Hua, VI, pp. 368-369)? Tais procedimentos metodológicos visam resgatar a evidência da idealidade numérica, a partir dos juízos que sedimentaram uma tradição científica, a qual é entendida como um conjunto de "atividades cognitivas que abarcam atos de intuição e de evidências; de expressões das compreensões desenvolvidas pelo sujeito, buscando explicitá-las e comunicá-las" (BICUDO, 2003a, p. 71).

No estudo da história em geral, mas especialmente na história dos números, é preciso considerar, por um lado, o aspecto subjetivo, que é o número na subjetividade da consciência, e, por outro, o aspecto objetivo, acessível como um objeto ideal. Edmund Husserl estava especialmente intrigado com a relação entre a objetividade ideal dos números, que é supratemporal, e a formação histórica de sentido. A concepção de número, historicamente, implica em uma gênese espiritual, pois o número é um produto no qual o ser humano elabora uma forma aos materiais previamente disponíveis (Hua, VI, pp. 367-372).

As condições ideais subjetivas possuem um papel especialmente importante na esfera da fundamentação das matemáticas e suas aplicações empíricas (Hua, XXIV, 2008, p. 119). O encaminhamento metodológico husserliano permitiria analisar os princípios da justificação do conhecimento matemático por meio de uma teoria das normas do conhecimento. A fundamentação buscada por Husserl viria, fenomenologicamente, da análise dos atos cognitivos, o que levantaria o problema da crítica do conhecimento a partir da teoria da ciência, complementando filosoficamente as atividades científicas.

Tomando a metodologia husserliana como referência (Hua, VI, pp. 365386), o objetivo do estudo da origem do número é descobrir o sentido mais originário em que ele foi concebido. A análise da origem do conceito descreve a maneira como o conceito se originou idealmente na consciência. Especificamente em Filosofia da Aritmética, o estudo da origem os números buscou a descrição do processo de abstração, incluindo a análise do fenômeno no qual a abstração baseou-se (DE BOER, 1978, p. 68; Hua XII, pp. 10-16, 130-131; MILLER, 1982; VARGAS, 2013).

A história fenomenológica dos números deve partir das atividades criadoras primeiras, considerando a formação do sentido (Sinnbildung) a partir de uma premissa original. Para voltar à origem (Ursprung), não é preciso voltar aos inventores imaginários, mas é possível resgatar a evidência da noção de número, analisando a estrutura noética que nos permitiu tornar presente e autêntica essa mesma noção. Reconhecendo o fenômeno tal e qual aparece à consciência, 
passa-se para a busca da origem de essências objetivas em uma subjetividade transcendental que antecede ou transcende a própria história. No caso do conhecimento autêntico do número, há um saber implícito, que surge da evidência originária a partir do solo do mundo da vida.

O sentido de número adotado será fenomenologicamente considerado como idealidade objetiva que se constitui historicamente por meio da intuição proporcionada pela evidência, envolvendo a empatia e a linguagem (BICUDO, 2003a, pp. 67-68; KLUTH, 2010). Assumindo a referência dos dados históricos, o filósofo busca revelar as características que fazem com que a ciência dos números possa ter uma validade permanente, fixando os seus significados e redescobrindo o sentido histórico da tradição científica, onde são sintetizados os resultados acumulados da pesquisa, colaborando na formação da ciência vivente (BICUDO, 2003b):

A cultura presente inteira, entendida como totalidade, "implica" o passado cultural completo [...] Ela implica numa continuidade de passados que se implicam entre si, cada um em si mesmo um presente cultural passado. E esta continuidade inteira é uma unidade de transmissão até o presente que é o nosso e, como vivacidade em si mesma fluente estável, é um tradicionalizar. [...] Assim, a evidenciação da geometria é, tenha-se ou não consciência disto, descobrimento da sua tradição (Hua, VI, pp. 379-380).

O processo histórico de elaboração de uma tradição é um movimento contínuo. Quando um matemático se engaja em um projeto, em um determinado momento histórico, pressupõe-se que ele seja membro de uma comunidade onde já exista uma tradição investigativa naquela área do conhecimento ou, pelo menos, na cultura em geral. O indivíduo constrói seus resultados a partir daquilo que foi obtido pelos outros pesquisadores. Edmund Husserl alertou que, ao assumir os resultados dos pesquisadores anteriores, nem sempre se consegue assumir as evidências originais e o conhecimento pode tornar-se inautêntico. Na perspectiva husserliana, a contribuição individual depende de uma tradição científica e precisa reativar a fonte original do conhecimento (CARR, 2010, p. 96).

O autor de A Origem da Geometria também indicou outras condições para a análise fenomenológica do número: primeiramente é preciso reativar o sentido 
ou a condição que permite a repetição de uma intuição dada, mas também exige-se a possibilidade da transmissão do conhecimento intuído. Além disso, Husserl inclui a condição de que o registro seja possível, assim como a sua compreensão, que, depois, será elaborada linguisticamente, elucidando o que não estava presente na evidência originária (Hua, VI, pp. 367-375; VARGAS, 2013).

Uma condição especialmente importante para que a matemática exista como ciência é a possibilidade do registro. O número, no âmbito científico, precisa ser registrado de alguma maneira, desde os meios tecnológicos mais recentes até o registro no papel ou até mesmo na própria memória. É justamente a possibilidade da repetição histórica, por meio da linguagem, que permite que a ciência seja realizada como, por exemplo, em uma lei matemática universal e permanente como o teorema de Euclides ${ }^{3}$.

Dentre os vários fatores relacionados com as condições de transmissão histórica do saber científico, que podem ser analisadas fenomenologicamente, Husserl destaca a linguagem universal, considerada no "horizonte da humanidade" (Hua, VI, pp. 369-373), reconhecendo que há um movimento da formação linguística inicial até assumir uma configuração objetiva que tende à universalidade. A condição comunicativa é um dos principais objetos de análise fenomenológica, inclusive em relação à história dos números, considerando a expressão da objetividade ideal dos números em uma tradição (VARGAS, 2013).

\section{Considerações finais}

Com sua filosofia fenomenológica, Edmund Husserl procurou resgatar o sentido original da filosofia, mas também das ciências, incluindo as matemáticas. Sem ser historicista, o filósofo alemão aproximou a clarificação epistemológica da explicação histórica quando afirmou que há, na origem das ciências, um "sentido histórico" que não é empírico. A história fenomenológica pode ser motivada pela identificação de uma crise do desenvolvimento científico e o seu respectivo impacto na sociedade em geral. Neste caso, como foi enfatizado por Eva-Maria Engelen (2010), as ciências não seriam analisadas apenas em termos de utilidade, mas também seriam consideradas em suas implicações filosóficas.

3 Em $A$ origem da geometria, Edmund Husserl cita o teorema de Pitágoras, mas, no estudo dos números, um exemplo poderia ser o teorema de Euclides, sobre a quantidade infinita de números primos, exposto na proposição 20 do livro IX da obra Elementos de Euclides (2005). 
A pesquisa sobre história fenomenológica dos números indica um caminho para que os filósofos, matemáticos e historiadores reflitam sobre as maneiras de adaptar as contribuições husserlianas à compreensão da estrutura da historicidade e da origem do número (BICUDO, 1999; KLUTH, 2005, pp. 56-57). Ao assumir a aplicação da metodologia fenomenológica, os ensinamentos da história são questionados. A compreensão filosófica das ciências, especialmente das matemáticas, pode ser reelaborada, na medida em que elas são consideradas atividades enraizadas no mundo da vida (VARGAS, 2013; ZILLES, 2007).

Assumindo a perspectiva metodológica da busca do sentido fundamental do número e da história, abre-se o caminho para outra compreensão do desenvolvimento das matemáticas. Se o tema da fenomenologia é a origem do mundo na constituição da subjetividade transcendental, o estudo fenomenológico da história colabora com a elucidação epistemológica da noção de número, oferecendo elementos filosóficos para a compreensão da coexistência vital das sedimentações dos significados matemáticos, incluindo reflexões sobre o mundo da vida e a própria estrutura histórica a priori.

Recebido em: 06.11.2013 | Aprovado em: 27.01.2014

BICUDO, Maria A. V. Filosofia da Educação Matemática: um enfoque fenomenológico. In: BICUDO, Maria A. V. (org.). Pesquisa em educação matemática: concepções e perspectivas. São Paulo: Ed. Unesp, 1999. pp. 21-44.

. Tempo, tempo vivido e história. Bauru: Edusc, 2003a.

- Concepção de história no pensar husserliano. In: NOBRE, Sérgio; TEIXEIRA, Marcos V. (ed.). Anais do V Seminário Nacional de História da Matemática. Rio Claro: SBHM, 2003b, pp. 125-140.

CARR, David. The Crisis as Philosophy of History. IN: HYDER, David; RHEINBERGER, Hans-Jörg (ed.). Science and the life-world: essays on Husserl's Crisis of European Sciences. Stanford: University Press, 2010, pp. 83-99.
COHEN, Joseph; MORAN, Dermot. The Husserl Dictionary. London: New York: Continuum, 2012.

DE BOER, Theodore. The Development of Husserl's Thought. Trad.: Theodore Plantinga. The Hague: Martinus Nijhoff Publishers, 1978.

ENGELEN, Eva-Maria. Husserl, History and Consciousness. IN: HYDER, David; RHEINBERGER, Hans-Jörg (ed.). Science and the life-world: essays on Husserl's Crisis of European Sciences. Stanford: University Press, 2010, pp. 136-149.

EUCLIDES. Elementos: Libros V-IX. Trad.: Maria L. P. Castaños. Madrid: Gredos, 2005.

FØLLESDAL, Dagfinn. The Lebenswelt in Husserl. IN: 
HYDER, David; RHEINBERGER, Hans-Jörg (ed.). Science and the life-world: essays on Husserl's Crisis of European Sciences. Stanford: University Press, 2010, pp. 27-45.

HEELAN, Patrick. Husserl's Philosophy of Science. In: MOHANTY, J.N.; MCKENNA, William R. (eds.). Husserl's Phenomenology: A Textbook. Washington: University Press of America, 1989, pp. 387-428.

HILL, Claire O. Did Georg Cantor Influence Edmund Husserl? Synthese, Dordrecht, 113, pp. 145-70, Oct. 1997

HUSSERL, Edmund G. A. Erfahrung und Urteil: Untersuchen zur Genealogie der Logik. Hrsg. von Ludwig Landgrebe. Prag: Academia Verlagsbuchhandlung, 1939

(Hua, XII) Philosophie der Arithmetik. Mit ergänzenden Texten (1890-1901). Hrsg. von Lothar Eley. Den Haag: Martinus Nijhoff, 1970 (Husserliana, Band XII).

(Hua, XIII) Zur Phänomenologie der Intersubjektivität. Texte aus dem Nachlass. Erster Teil. 1905-1920. Hrsg. von Iso Kern. Den Haag: Martinus Nijhoff, 1973 (Husserliana, Band XIII).

. (Hua, XVIII) Investigações Lógicas: Primeiro Volume - Prolegómenos à Lógica Pura. Trad.: Diogo F. Ferrer. Lisboa: Centro de Filosofia. De acordo com o texto de Logische Untersuchungen. Erster Teil. Prolegomena zur reinen Logik. Text der 1. und der 2. Auflage. Hrsg.: Elmar Holenstein. Den Haag: Martinus Nijhoff, 1975 (Husserliana, Band XVIII).

(Hua, VI) A Crise das Ciências Europeias e a Fenomenologia Transcendental: Uma Introdução à Filosofia Fenomenológica. Trad.: Diogo F. Ferrer. Rio de Janeiro: Forense Universitária, 2012. De acordo com o texto de Die Krisis der europäischen Wissenschaften und die transzendentale Phänomenologie. Eine Einleitung in die phänomenologische Philosophie. Hrsg.: Walter Biemel. Den Haag: Martinus Nijhoff, 1976 (Husserliana, Band VI). (Hua, XXIV) Einleitung in die Logik und
Erkenntnistheorie: Vorlesungen 1906/07. Hrsg.: Ullrich Melle. Dordrecht: Kluwer Academic Publishers, 1984 (Husserliana, Band XXIV).

. (Hua, XXIX) Die Krisis der europäischen Wissenschaften und die transzendentale Phänomenologie. Ergänzungsband. Texte aus dem Nachlass (1934-1937). Hrsg.: Reinhold Smid. Dordrecht: Kluwer Academic Publishers, 1993 (Husserliana, Band XXIX).

IERNA, Carlo. La notion husserlienne de multiplicité: audelà de Cantor et Riemann. Trad.: C. Majolino. Methodos [En ligne], Paris, Déc. 2012. Disponível em: <http:// methodos.revues.org/2943>. Acesso em: 12 dez. 2012.

KLUTH, Verilda S. 2005. Estruturas da álgebra: investigação fenomenológica sobre a construção do seu conhecimento. Rio Claro. 194p. 2005. Tese (Doutorado em Educação Matemática). Instituto de Geociências e Ciências Exatas, Universidade Estadual Paulista. . Panorama fenomenológico sobre número e sua imagem na alfabetização aritmética. In: BICUDO, Maria A. V. (org.). Filosofia da Educação Matemática: fenomenologia, concepções, possibilidades didáticopedagógicas. São Paulo: Ed. Unesp, 2010.

MILLER, J. Philip. Numbers in Presence and Absence: A Study of Husserl's Philosophy of Mathematics. The Hague: Martinus Nijhoff Publishers, 1982.

SILVA, Marcela M. M. Razão e historicidade no último Husserl. Scientiæ Studia, São Paulo, v. 7, n. 4, pp. 653-58, 2009.

SMITH, David W. Science, Intentionality, and Historical Background. IN: HYDER, David; RHEINBERGER, Hans-Jörg (ed.). Science and the life-world: essays on Husserl's Crisis of European Sciences. Stanford: University Press, 2010, pp. 27-45.

TIESZEN, Richard. Science as a Triumph of the Human Spirit and Science in Crisis: Husserl and the Fortunes of Reason. In: GUTTING, Gary. Continental Philosophy of 
Science. Oxford: Blackwell Publishing, 2005, pp. 93-112.

VARGAS, Carlos E. C. Sobre a Origem dos Números. In: V TECSOC Esocite.BR - Simpósio Nacional de Tecnologia e Sociedade. Ciência, tecnologia e cultura: outro desenvolvimento é possível? Anais. Curitiba: UTFPR: Esocite.BR, 2013, pp. 1116-1124.

ZILLES,Urbano.FenomenologiaeTeoriado Conhecimento em Husserl. Revista da Abordagem Gestáltica, Goiânia, v. XIII, n. 2, pp. 216-221, jul. 2007.

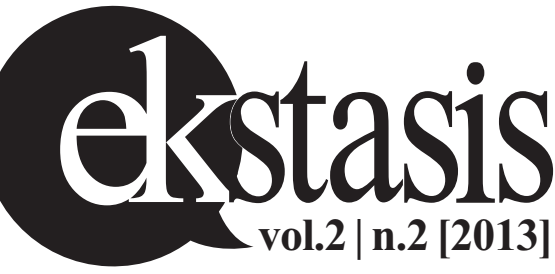

